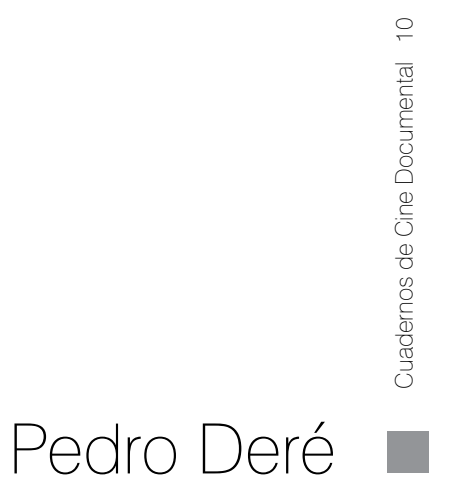

\title{
Una historia personal
}

En 1982 varios jóvenes de alrededor de 20 años, entre los cuales estaba Sergio Delgado, fundamos Proarte. Durante varios años realizamos un Festival de Cine argentino, y hacia el 87 , no conforme con mostrar cine, me inscribí en el Taller de Cine, para aprender a hacer cine. Las clases de Raúl y de Marilyn hicieron que poco a poco, me dedicara exclusivamente a trabajar en cine, abandonando, entre otras cosas, mi carrera de arquitecto.

Después de un 88 memorable, donde se filmó muchísimo (Nadie nada nunca en $35 \mathrm{~mm}$., Zenón Pereyra en $16 \mathrm{~mm}$., 8 ejercicios de filmación en $16 \mathrm{~mm}$.), el Convenio con el INC (gracias al cual se filmaron Candidato, Reencuentro, Homenaje a Juan L. Ortiz), llegó el 89, y llegó el Video.

Al principio cinco jóvenes que trabajamos en Nadie nada nunca compramos una pequeña cámara Sony Video 8. Con esa cámara filmé Enfrente. Éramos cineas- tas convertidos en videastas pobres: se reciclaban casetes, no se pensaba en ningún crecimiento del Taller. En el 2000 el Taller se incorpora a la era digital, y gracias al apoyo del entonces Secretario de Extensión, José Corral, tuvimos cámaras Video 8, luego Hi8, luego Digital 8 , y el montaje se realizó en diversos equipamientos, que concluyeron con la computadora G4 y el programa Final Cut Pro. Se fundó el Centro de Producción de Video y se colaboró con la filmación y el montaje de varias video-películas de Rafael Filippelli. Hice el montaje on-line de Érase una vez la poesía, de Juan Carlos Arch, en la que participaban Fernando Birri y Gastón Gori, lo que me permitió conocer el Wire-Fire. En su momento fotógrafos de Buenos Aires, como Paola Rizzi y Germán Drexler, participaron en producciones del Taller.

Hoy tenemos un catálogo de 90 películas y festejamos en este Encuentro los 30 años del Taller de Cine. 
2015 fue un año de festejo para el Taller de Cine de la UNL, al cumplirse 30 años de su funcionamiento ininterrumpido. Desde 1985, retomando una larga tradición del cine en la Universidad Nacional del Litoral que comienza con el Instituto de Cinematografía fundado por Fernando Birri en 1956, el Taller de Cine ha formado decenas de cineastas, ha dado cursos para centenares de interesados en la realización cinematográfica, organizado ciclos de proyecciones a los que asistieron miles de espectadores y ha producido alrededor de 90 películas, entre cortometrajes y largometrajes, documentales y películas de ficción, realizados ya por cineastas debutantes o por realizadores con experiencia.
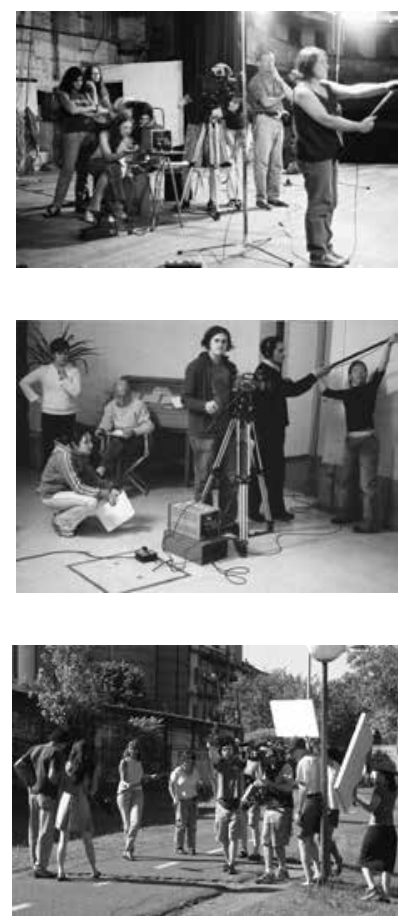
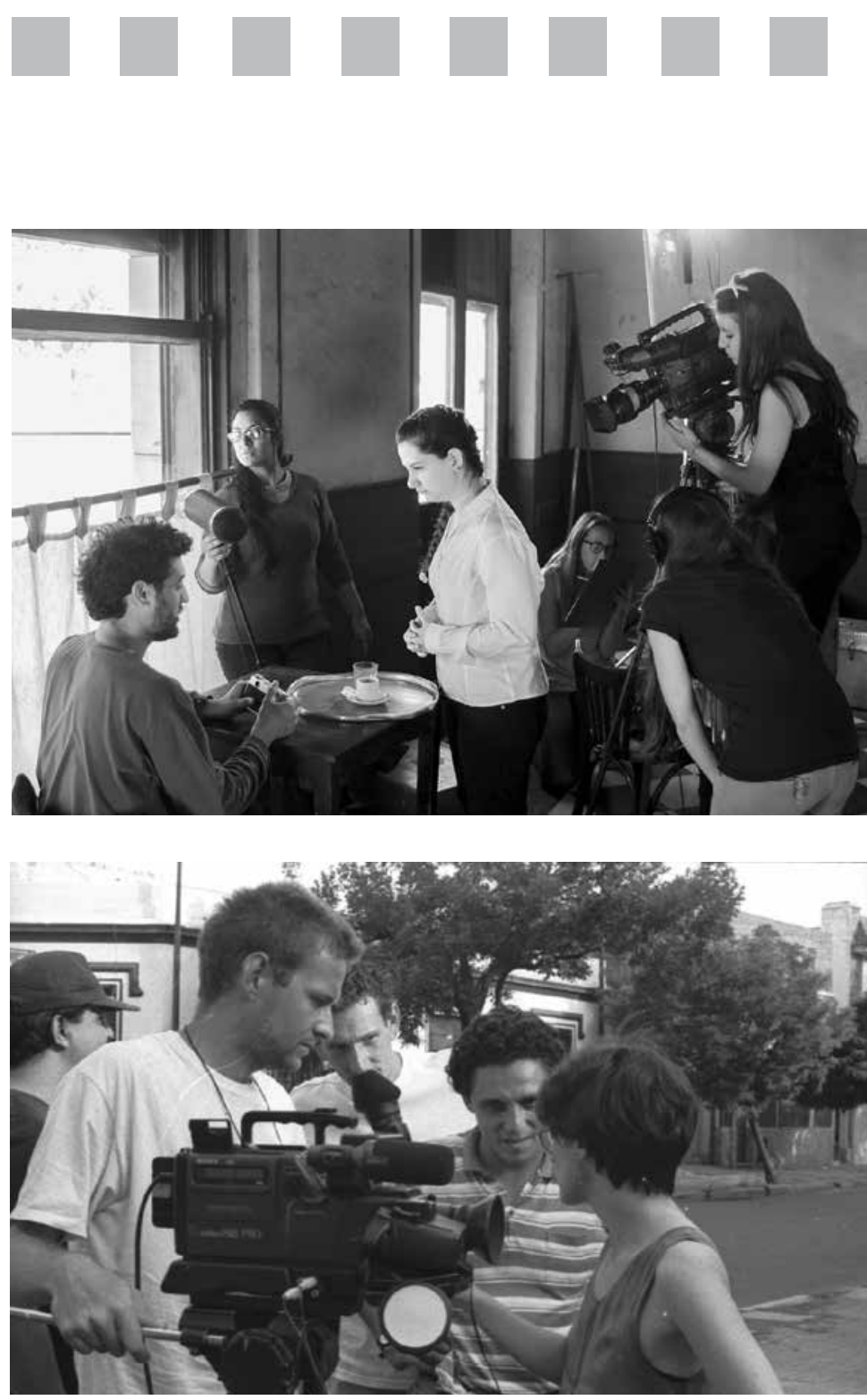

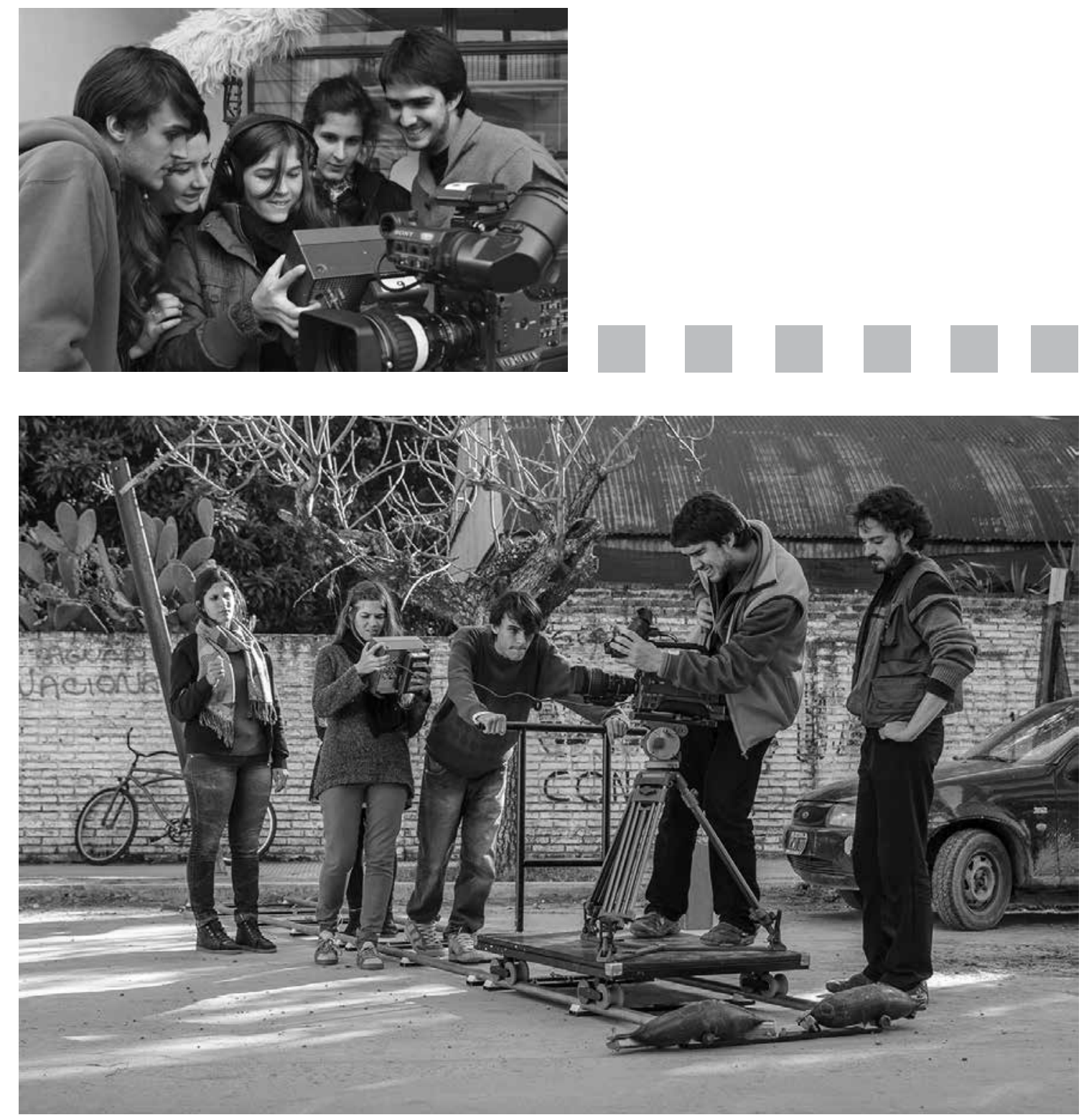
